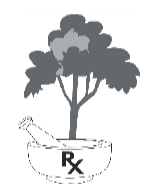

https://dx.doi.org/10.4314/jpb.v18i3.3

Vol. 18 no. 3, pp. 192-195 (September 2021)

http://ajol.info/index.php/jpb

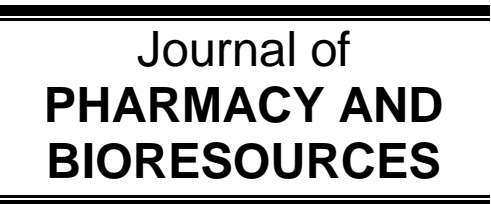

\title{
One-pot synthesis of $N$-benzyl-2-aminobenzoic acid, via ring opening of isatoic anhydride derivative, and its antibacterial screening
}

\author{
Emmanuel E. ODION*, Gbemisola AJIBOSIN and Cyril O. USIFOH \\ Department of Pharmaceutical Chemistry, Faculty of Pharmacy, University of Benin, Benin City. Nigeria. \\ Received $8^{\text {th }}$ April 2021; Accepted $3^{\text {rd }}$ August 2021
}

\begin{abstract}
2-( $N$-Benzyl) amino benzoic acid is a bifunctional molecule that could be produced from the reaction between isatoic anhydride and aryl halide. Analogues and derivatives of isatoic anhydride have wide application in pharmaceuticals including antibacterial activity. The aim of this study is to synthesize, characterize and screen $N$-benzyl isatoic anhydride and 2-( $N$-benzyl) amino benzoic acid for antibacterial activity. The reaction of isatoic anhydride and benzyl bromide in the presence of potassium carbonate in DMSO at room temperature yielded $N$-benzyl isatoic anhydride, which under hydrolysis yielded 2-( $N$-benzyl $)$ amino benzoic acid in which the anhydride ring is opened up. This compound was screened against Gram positive and negative bacteria. Moderate yield of 2-( $N$-benzyl) amino benzoic acid, a yellow crystal (melting point of $160-162^{\circ} \mathrm{C}$, percentage yield $65 \%, \mathrm{R}_{\mathrm{f}} 0.19$ ) formed by ring opening of $N$ benzyl isatoic anhydride. The compound showed no antibacterial activity against Escherichia coli, Staphylococcus aureus, Pseudomonas pyocyanea, Salmonella typhimurium, Klebsiella aeruginosa and Bacillus subtilis. 2-(N-benzyl) amino benzoic was synthesized, characterized and showed no activity against bacteria.
\end{abstract}

Keywords: 2-( $N$-benzyl) amino benzoic; $N$-benzyl isatoic anhydride; Hydrolysis; Antibacterial

\section{INTRODUCTION}

The coupling of isatoic anhydride with other molecules have resulted in compounds with anti-inflammatory, analgesic and antimicrobial properties [1]. Such compounds include anthranilamide and $o$-ureidobenzoic acid, which are derive from the synthetic reactions between isatoic anhydride with ammonia, primary, secondary amines and amide. Also, isatoic anhydride reacts with other nucleophilic reagents like primary and secondary alcohols, phenols, thiophenol and mercaptans [2], some of these reactions could lead to opening of the synthesized chain or ring.

Benzoic acid has antimicrobial effect with relatively low toxicity [3]. Due to its low cost, colourless nature and its relatively low toxicity, it is popularly used as a preservative [4]. Benzoic acid and its derivatives have shown antibacterial activity and assisted in the removal of exfoliated cells. Discovered to be eligible for Chagas disease treatment through different biological mechanism and also show significant trypanocidal activity [5]. Reaction involving isatoic anhydride, amine and benzyl

*Correspondence. E-mail: emmanuel.odion@uniben.edu Tel: +234-9048303020.

ISSN 0189-8442

2021. Published by Faculty of Pharmaceutical Sciences, University of Jos, Nigeria. Under Creative Commons Attribution-Non-Commercial 4.0 International License. https://creativecommons.org/licenses/by-nc/4.0/ 
halide gave an excellent yield of 4(3H)quinazolinones [6], with antimicrobial activity [1].

Following the discovery of antibiotics, significant amounts of antimicrobials have been synthesized, which have impacted human health positively and reduced mortality rates globally [7]. However excessive and over the counter dispensing of antibiotics in developing nations and their irresponsible use, have resulted in the development of resistant strains of bacteria. Internationally, efforts geared towards developing novel drugs or transforming current drugs to combat resilient microbes are ongoing [8]. Resistance to antibiotics occurs by different methods and has become a growing crisis in clinical medicine [9]. This study aimed to react benzyl bromide with isatoic anhydride in order to synthesize $N$ benzyl isatoic anhydride and 2-(N-benzyl) amino benzoic acid. These compounds were characterized and screened for antibacterial activity.

\section{EXPERIMENTAL METHODS}

All reagents were sourced from reputable manufacturers. Melting point for the synthesized compound was evaluated on MelTemp capillary instrument (Staffordshire, UK). Frontier-transform infrared (FTIR-8400S equipment, Shimadzu global link, North America) was used to determine the IR spectrum of the compound. ${ }^{1} \mathrm{H}$ NMR spectrum was acquired using Bruker Avance-300 spectrometer at $200 \mathrm{MHz}$ (AXS Inc., USA), using $\mathrm{CDCl}_{3}$ as solvent and tetramethylsilane as internal standard. Thin layer chromatography (TLC) was used to monitor the purity and reactions and chromatograms were viewed under UV at 230-245 nm

Synthetic methods. To isatoic anhydride ( $3 \mathrm{~g}$, $0.018 \mathrm{~mole}$ ) and $2.187 \mathrm{~g}$ of anhydrous potassium carbonate in a $250 \mathrm{ml}$ flask was added $25 \mathrm{ml}$ of dimethyl sulphoxide (DMSO) at room temperature with stirring. Benzyl bromide (2.39 ml, 0.02 mole) was added after
15 minutes and the mixture was continuously stirred. The reaction was stopped after 20 hours and the mixture introduced gently into a conical flask containing cold water while stirring. The mixture was filtered, then the precipitate collected.

Column chromatography was carried out on the crude product obtained using chloroform-ethyl acetate $(9: 1)$ to purify the compound and recrystallized from chloroform.

Antibacterial activity. The bacteria culture isolates (Escherichia coli, Staphylococcus aureus, Pseudomonas pyocyanea, Salmonella typhimunium, Klebsiella aeruginosa and Bacillus subtilis) used for this study were obtained from University of Benin Teaching Hospital and microbial bank of the Department of Pharmaceutical Microbiology, Faculty of Pharmacy, University of Benin. The strains were cultured, sub-cultured in sterile nutrient agar plate at $37^{\circ} \mathrm{C}$ for 48 hours and standardized to $10^{6} \mathrm{CFU} / \mathrm{ml}$ for 12 hours before use. $0.2 \mathrm{ml}$ of 2 -( $N$-benzyl $)$ aminobenzoic acid $(1 \mathrm{mg} / \mathrm{ml})$ was dissolved in DMSO as a diluent (negative control) and ciprofloxacin $(10 \mathrm{mcg} / \mathrm{ml})$ was used as the standard. The zones of inhibition were measured in millimetres and compared with the control standards using the method described by Bonev et al., [10]. The antibiotic susceptibility testing was determined using Kirby-Bauer modified diffusion technique, which involves swabbing Mueller-Hinton agar (MHA), plates with the resultant saline suspension of each strain and six wells were aseptically bored using size $6 \mathrm{~mm}$ cork borer on the agar surfaces seeded with the test organisms. The wells were sealed at the bottom with molten sterilized agar. Stock solutions of the synthesized compounds were prepared by dissolving $500 \mathrm{mg}$ of each in $5 \mathrm{~mL}$ DMSO to give a concentration of $100000 \mathrm{mcg} / \mathrm{mL}$. Then $0.1,0.05,0.025$ and $0.0125 \mathrm{~mL}$ of the stock corresponding to $10000,5000,2500$ and 1250 $\mathrm{mcg} / \mathrm{mL}$ respectively, of the synthesized compounds were aseptically introduced into 
the agar wells, were prepared aseptically and transferred to the wells. The ciprofloxacin antibacterial discs were also placed on the agar surface. The plates were left undisturbed on the bench for 30 minutes to enable the agar to absorb the compounds adequately, incubated for 24 hours at $37^{\circ} \mathrm{C}$ and observed for confluent growth of the microorganisms and clear zones of inhibition around the samples in the agar wells [11].

\section{RESULTS AND DISCUSSION}

A moderate yield of 2-(N-benzyl) aminobenzoic acid (65\%) was obtained, with a melting point of $172-174^{\circ} \mathrm{C}$, which differ significantly from the melting point of the starting materials isatoic anhydride of $\left(233^{\circ} \mathrm{C}\right)$ and benzyl bromide $\left(-3.9^{\circ} \mathrm{C}\right)$. The reaction yielded a closed ring compound (benzylated isatoic anhydride), which on hydrolysis gave an opened compound with the loss of carbon dioxide $\left(\mathrm{CO}_{2}\right)$. The proton nuclear magnetic resonance ( ${ }^{1} \mathrm{H}$ NMR) of the synthesized compound revealed five protons environments. The protons from $\mathrm{NH}$ and $\mathrm{OH}$ were not observed in the spectrum due to their easily exchangeable nature, since deuterated chloroform was the solvent used for running the NMR experiment The characteristic signal at $4.40 \mathrm{ppm}$ was attributed to methylene $\left(\mathrm{CH}_{2}\right)$ hydrogen appearing as a singlet. A triplet signal was observed at $6.5 \mathrm{ppm}$ due to aromatic (-CH) hydrogen surrounded by two methine ($\mathrm{CH}$ ) hydrogen in the same environment at 6.62 ppm. Another double doublet was seen at 7.90 ppm for an aromatic methine (-CH) hydrogen. The ${ }^{13} \mathrm{C}-\mathrm{NMR}$ spectrum showed a diagnostic chemical shift at $170.61 \mathrm{ppm}$ due to the carbonyl in the carboxylic functional moiety. Mass spectrometry showed the base peak at $180 \mathrm{~m} / \mathrm{z}$, the molecular ion $\left(\mathrm{M}^{+}\right)$at $227 \mathrm{~m} / \mathrm{z}$ which corresponds to the molecular weight.

2-(N-Benzyl) amino benzoic acid: $0.90 \mathrm{~g}, 65 \%$; melting point $172-174^{\circ} \mathrm{C} ; \mathrm{R}_{\mathrm{f}} 0.19 . \mathrm{IR}\left(\mathrm{KBr} \mathrm{cm}^{-1}\right)\left(3453\left(\mathrm{NH}_{2}\right), 3400\right.$ $(\mathrm{OH}), 1760$ (CO), $1620(\mathrm{C}=\mathrm{C}) \div{ }^{1} \mathrm{H}$ NMR $\left(200 \mathrm{MHz} \mathrm{CDCl}_{3}\right): \delta 4.40\left(\mathrm{~s}, 2 \mathrm{H}, \mathrm{CH}_{2}\right) ; 6.5(\mathrm{t}, \mathrm{J}=7.00 \mathrm{~Hz}, 1 \mathrm{H}, \mathrm{ArH}) ; 6.62$ $(\mathrm{d}, \mathrm{J}=7.51 \mathrm{~Hz}, 1 \mathrm{H}, \mathrm{ArH}) ; 7.10-7.40(\mathrm{~m}, 6 \mathrm{H}, \mathrm{ArH}) ; 7.90$ (dd, J=1.53, 8.03Hz, $1 \mathrm{H}, \mathrm{Ar}-\mathrm{H}) .{ }^{13} \mathrm{C}-\mathrm{NMR}(50 \mathrm{MHz}, \mathrm{CDCl} 3)$ : $\delta 44.00,112.00,115.00,126.70,127.70,131.90,134.10$. MS 227 (96), 209 (70), 180 (100), 121 (7), 91 (57), 77 (16), 65 (26); Elemental analysis: $\mathrm{C}_{14} \mathrm{H}_{13} \mathrm{NO}_{2}$ (227), Cal.: C. 73.99 H. 5.77 N. 6.17, Found C. 73.77 H. 5.68 N.6.28.

Table 1: Anti-bacterial activity (Zone of inhibition - $\mathrm{mm}$ ) of test compounds

\begin{tabular}{lllllll}
\hline Test compound & S. aureus & E. coli & P. pyocyanea & S. typhimurium & K. aeruginosa & B. subtilis \\
\hline $\begin{array}{l}\text { 2-(N-Benzyl) } \\
\text { amino benzoic acid }\end{array}$ & $0.00 \pm 0.00$ & $0.00 \pm 0.00$ & $0.00 \pm 0.00$ & $0.00 \pm 0.00$ & $0.00 \pm 0.00$ & $0.00 \pm 0.00$ \\
Ciprofloxacin & $20 \pm 0.30$ & $24 \pm 0.30$ & $16 \pm 0.20$ & $21 \pm 0.30$ & $18 \pm 0.30$ & $19 \pm 0.20$ \\
DMSO & $0.00 \pm 0.00$ & $0.00 \pm 0.00$ & $0.00 \pm 0.00$ & $0.00 \pm 0.00$ & $0.00 \pm 0.00$ & $0.00 \pm 0.00$ \\
\hline
\end{tabular}

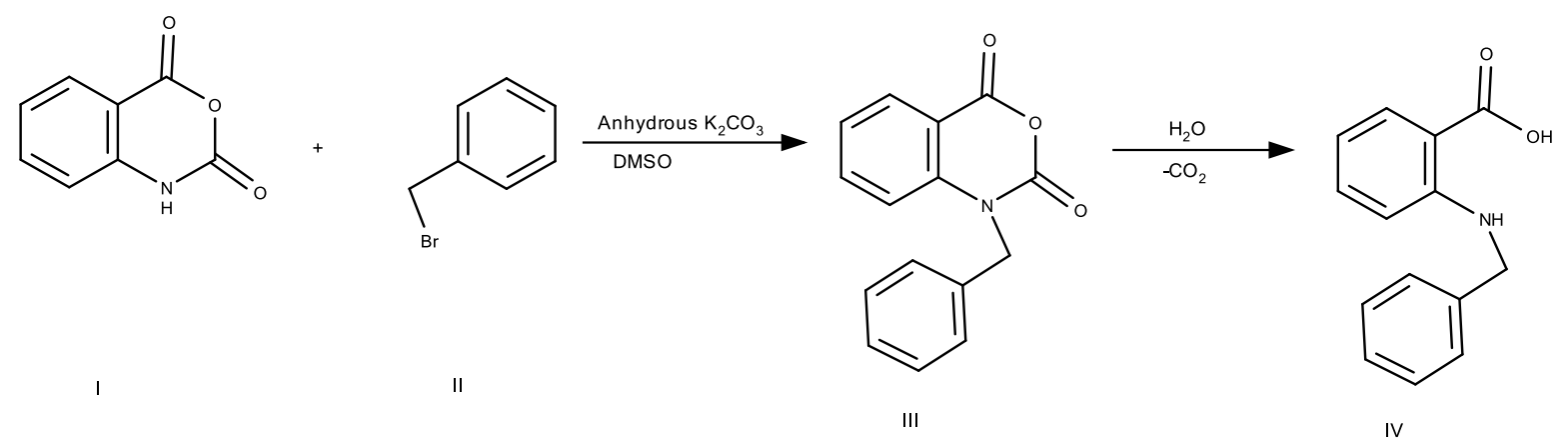

- $\quad$ Scheme 1

The synthesis of 2-(N-benzyl) aminobenzoic acid via $N$-benzyl isatoic anhydride which was a reaction between isatoic anhydride and benzyl bromide as illustrated in Scheme 1. The reaction between isatoic anhydride (I) and benzyl bromide (II) at 
room temperature in the presence of potassium carbonate, using DMSO as the solvent, yielded a closed ring compound $N$-benzyl isatoic anhydride (III) which on hydrolysis yield an open ring compound $N$-benzyl-2aminobenzoic acid (IV), after the loss of carbon dioxide. The reaction proceeded via substitution nucleophilic reaction $\left(\mathrm{SN}_{2}\right)$, which involved the replacement of the hydrogen on the $-\mathrm{NH}$ in isatoic anhydride by benzyl ion from benzyl bromide at room temperature in DMSO. This was facilitated by potassium carbonate acting as a base, yielding the $\mathrm{N}$ benzyl isatoic anhydride.

Dimethyl sulphoxide (DMSO) was used as a solvent for ciprofloxacin (positive control) and test compound. It was observed that DMSO (negative control) did not show any activity against the bacteria used in this study, while ciprofloxacin showed activity against these bacteria. Also, the synthesized compound showed no antibacterial activity against gram-positive and negative bacteria see Table 1.

Conclusion. In this study, a moderate yield of 2-(N-benzyl) aminobenzoic acid was synthesized, which showed no activity against Escherichia coli, Staphylococcus aureus, Pseudomonas pyocyanea, Salmonella typhimurium, Klebsiella aeruginosa and Bacillus subtilis when compared with commercially available drug ciprofloxacin.

\section{REFERENCES}

1. Abbas, S. Y. (2020). 4(3H)-Quinazolinone Derivatives: Syntheses, Physical Properties, Chemical Reaction, and Biological Properties. doi: 10.5772/intechopen.9.

2. D’Souza, A. M., Spiccia, N., Basutto, J., Jokisz, P., Wong, L. S. M., Meyer, A.G., Holmes, A.B., White, J.M., Ryan, J.H. (2011). 1,3-Dipolar
Cycloaddition-Decarboxylation Reactions of an Azomethine Ylide with Isatoic Anhydrides: Formation of Novel Benzodiazepinones. Organic Letters. 13 (3), 486-489. doi: 10.1021/ol102824k.

3. Chipley, J.R. (2005). Sodium Benzoate and Benzoic Acid. Antimicrobials in Food (pp.11-48). doi:10.1201/9780429058196-3.

4. Davidson, P. M., Taylor, T. M., Schmidt, S. E. (2013). Chemical Preservatives and Natural Antimicrobial Compounds. In Food Microbiology. American Society of Microbiology. pp. 765-80. Doi.org/10.1128/9781555818463.ch30.

5. Kashif, M., Moreno-Herrera, A., Villalobos-Rocha, J.C., Nogueda-Torres, B., Pérez-Villanueva, J., Rodríguez-Villar, K., Medina-Franco, J. L., de Andrade, P., Carvalho, I., Rivera, G. (2017). Benzoic Acid Derivatives with Trypanocidal Activity: Enzymatic Analysis and Molecular Docking Studies toward Trans-Sialidase. Molecules; 22(11): 1863. Doi.10.3390/molecules22111863.

6. Adib, M., Sheikhi, E., Bijanzadeh, H.R. (2012). OnePot Three-Component Synthesis of 4(3H)Quinazolinones from Benzyl Halides, Isatoic Anhydride, and Primary Amines Synlett, 23, 85-88. DOI: $10.1055 / \mathrm{s}-0031-1290098$.

7. Breijyeh Z, Jubeh B, Karaman R. (2020). Resistance of Gram-negative Bacteria to Current Antibacterial Agents and Approaches to Resolve it. Molecules. 16; 25(6):1340. doi:10.3390/molecules25061340.

8. Silhavy TJ, Kahne D, Walker S. (2010). The Bacteria Cell Envelope. Cold Spring Harb Perspect Biology. 2(5):a000414. Doi:10.1101/cshperspect.a000414.

9. Nathan C. and Cars O. (2014). Antibiotics ResistanceProblem, Progress and Prospect. (2014). New England Journal of Medicine. 371:1761-1763. Doi:10.1056/NEjMp1408040.

10. Bonev, B., Hooper, J., Parisot, J. (2008). Principles of assessing bacterial susceptibility to antibiotics using the agar diffusion method. Journal of antimicrobial chemotherapy. 61(6):1295-1301.

11. Babaiwa U.F. Akerele, J., (2017). Antimicrobial activity of ethyl acetate extract of Citrullus lanatus seeds. Tropical Journal of Pharmaceutical Research.16 (7): 1631-1636. 